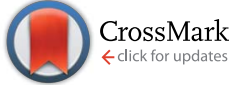

Cite this: RSC Adv., 2014, 4, 32081

\title{
Cattle fat valorisation through biofuel production by hydrogenation in supercritical carbon dioxide
}

\author{
Ana R. C. Morais, ${ }^{a}$ Andre M. da Costa Lopes, ${ }^{a}$ Paula Costa, ${ }^{\mathrm{b}}$ Isabel Fonseca, ${ }^{\mathrm{c}}$ \\ Isabel N. Nogueira, ${ }^{d}$ Ana C. Oliveira ${ }^{a}$ and Rafal Bogel-Lukasik ${ }^{\star a}$
}

The use of residues or wastes in biofuel production is a potential solution to the questioned increase of the food market price. The hydrogenation (more specifically hydrodeoxygenation) of residues or wastes rich in free fatty acids seems to be an interesting option for the valorisation of this type of feedstock. The major obstacle of this process is the high temperature and high $\mathrm{H}_{2}$ pressure process requirement. The way to reduce it is the use of a co-solvent e.g. supercritical fluids. At supercritical conditions, $\mathrm{CO}_{2}$ is completely miscible with $\mathrm{H}_{2}$ and at the same time is also a great solvent for non-polar liquids allowing enhanced efficiency of the hydrogenation leading to the ability to perform reactions at milder conditions. This work deals with the heterogeneous hydrogenation of cattle fat in the presence of $\mathrm{CO}_{2}$. Total reaction pressures up to 140 bar at $340{ }^{\circ} \mathrm{C}$ and the residence time from 1 to 6 hours as well as the reuse of catalyst were examined. Depending on the chosen reaction conditions a diverse end products can be obtained. The $\mathrm{CO}_{2}$ presence influences positively the concentration of hydrocarbons minimising the presence of glycerides' content in the final product mixture. At elevated $\mathrm{CO}_{2}$ pressure, a high concentration of hydrocarbons simultaneously with a low presence of free fatty acids and glycerides' content in the mixture was obtained. A similar effect was observed for reaction carried out for 6 hours, when above $90 \mathrm{wt} \%$ of all hydrocarbons present in the mixture were the saturated ones. Additionally, the reuse of catalyst increases the saturated hydrocarbons' content to values similar to those obtained for reactions with prolonged residence time. In the $\mathrm{CO}_{2}$-assisted reactions, the diesel-like hydrocarbons were formed with at least two fold higher content than in reactions without $\mathrm{CO}_{2}$.

Received 2nd June 2014

Accepted 2nd July 2014

DOI: $10.1039 / c 4 r a 05225 \mathrm{k}$

www.rsc.org/advances

\section{Introduction}

Nowadays the use of renewable resources for the transport sector is an obligation established by the renewable energy directive. ${ }^{1}$ This Directive endorsed a mandatory $10 \%$ minimum target to be achieved by all Member States for the share of biofuels and other renewable fuels by 2020 . The most common approach, practiced by the EU member states, to achieve this target, is the production of $1^{\text {st }}$ generation biofuels from virgin vegetable oils such as the ones from rapeseed, soybean and sunflower. However, the applicability of these edible oils for fuel production is strongly criticised due to the influence on the food market price. To minimise this influence, the European

\footnotetext{
${ }^{a}$ Unidade de Bioenergia, Laboratório Nacional de Energia e Geologia, I.P., Estrada do Paço do Lumiar 22, 1649-038 Lisboa, Portugal. E-mail: rafal.lukasik@lneg.pt; Fax: +351217163636; Tel: +351210924600 ext. 4224

${ }^{b}$ Unidade de Tecnologias de Conversão e Armazenamento de Energia, Laboratório Nacional de Energia e Geologia, I.P., Estrada do Paço do Lumiar 22, 1649-038 Lisboa, Portugal

${ }^{c}$ REQUIMTE, Departamento de Química, Faculdade de Ciências e Tecnologia, Universidade Nova de Lisboa, 2829-516, Caparica, Portugal

${ }^{d}$ Instituto de Ciência e Engenharia de Materiais e Superfícies, Instituto Superior Técnico, Universidade de Lisboa, Lisboa, Portugal
}

Commission is forcing a limit of $5 \%$ of biofuels originating from the $1^{\text {st }}$ generation feedstock. ${ }^{2}$ Consequently, exploration of new ways to reduce feedstock cost and the development of alternative raw materials are key points in recent biofuels' research. The use of residues or wastes might be a solution offering a much more competitive price of the final biodiesel and opening a new route to recycle and to valorise residues and wastes. However, it is also important to underline that valorisation of this type of feedstock is more technologically demanding compared to the existing technologies. The major obstacle is the high free fatty acid (FFA) content, which may render low yield of biodiesel production processes. ${ }^{3}$ The recent developments in this field show promise to overcome this problem. $^{4-6}$

One of the methods of valorisation of wastes rich in free fatty acids is hydrogenation or more precisely, hydrodeoxygenation. This process leads to production of hydrogenated oil and involves the catalytic hydrogenation and cracking of raw material. The use of $\mathrm{H}_{2}$ guides to the removal of oxygen and hydrocarbons' formation. In addition, depending on the applied conditions (pressure, temperature, catalyst) the produced hydrocarbons' fraction can be similar to gasoline or diesel. Therefore, the formed products can be either mixed with crude- 